
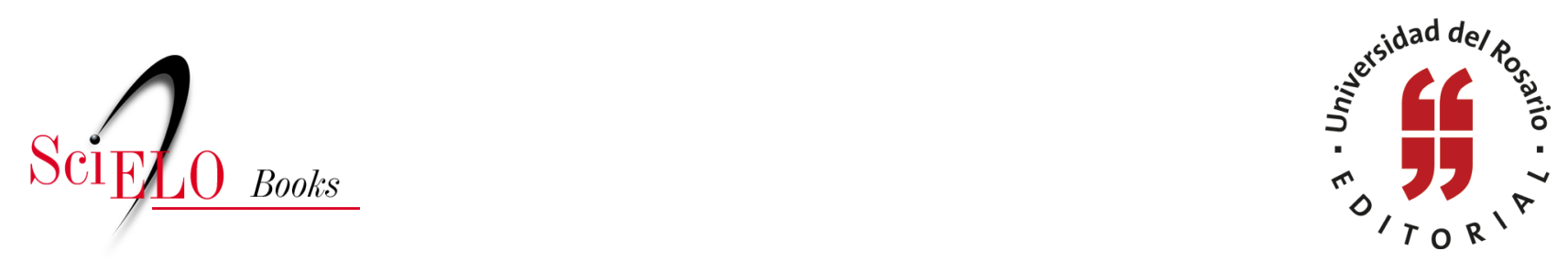

\title{
Entre la fragilidad y la vigencia. Uma reflexión sobre la comunidad. Caso El Codito
}

\author{
Mónica Mendoza Molina
}

\section{SciELO Books / SciELO Livros / SciELO Libros}

MOLINA, M.M. Entre la fragilidad y la vigencia. Una reflexión sobre la comunidad. Caso El Codito. In: SALAMANCA, J.D.G., GARCÍA, M.H., and MOLINA, M.A.M. Construcción y significación del territorio. Comunidad El Codito, 2011 [online]. Bogotá: Editorial Universidad del Rosario, Instituto Rosarista de Acción Social - SERES, 2013, pp. 22-54. ISBN 978-958-784-206-7.

https://doi.org/10.7476/9789587842067.0002.

All the contents of this work, except where otherwise noted, is licensed under a Creative Commons Attribution 4.0 International license.

Todo o conteúdo deste trabalho, exceto quando houver ressalva, é publicado sob a licença Creative Commons Atribição $\underline{4.0}$.

Todo el contenido de esta obra, excepto donde se indique lo contrario, está bajo licencia de la licencia Creative Commons $\underline{\text { Reconocimento } 4.0 .}$. 


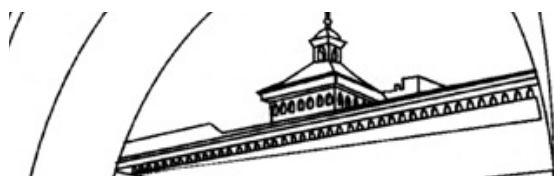




\title{
Entre la fragilidad y la vigencia. Una reflexión sobre la comunidad. Caso El Codito
}

\author{
Mónica Mendoza Molina*
}

* Socióloga de la Universidad Nacional de Colombia. Actualmente se desempeña como coordinadora de investigación social del Instituto Rosarista de Acción Social Rafael Arenas Ángel —Seres— de la Universidad del Rosario. Correo electrónico: monica.mendoza@urosario.edu.co. 
Es en verdad evidente que a pesar de un alejamiento posterior los Hobbits son parientes nuestros: están más cerca de nosotros que los Elfos y aun que los mismos Enanos. Antiguamente hablaban las lenguas de los Hombres, adaptadas a su propia modalidad, y tenían casi las mismas preferencias y aversiones que los Hombres. Mas ahora es imposible descubrir en qué consiste nuestra relación con ellos. J.R.R Tolkien, El señor de los anillos.

\section{Introducción}

El presente texto es uno de los resultados construidos con base a un ejercicio realizado por el equipo interdisciplinario de estudios en desarrollo local de la Universidad del Rosario, en el sector El Codito, de la localidad de Usaquén en Bogotá. El trabajo de la Universidad en este territorio se remonta al año 2007 y desde allí se han adelantado acciones concretas, proyectos y trabajos conjuntos con la comunidad que, en algunos casos, se han materializado en textos académicos (ver Luna, E., 2010, pp. 109-139 y Guevara, J. \& Mendoza, M., 2011).

La información aquí contenida, se enmarca en el interés del equipo interdisciplinario y de algunos sectores de la población de El Codito, por entender las formas que propician o dificultan la construcción de comunidad en el sector, así como la función que desempeña el territorio en esta labor.

Inicialmente, se realiza un recorrido por la evolución del término 'comunidad', a la luz de algunos teóricos de la sociología, que plantean características generales del término, controversias en torno al mismo y binomios que aún guardan vigencia en algunos ámbitos, tales como individuosociedad o comunidad-sociedad. Las características observadas en campo serán contrastadas con estos planteamientos y con la percepción que los mismos pobladores tienen del lugar que habitan y de las relaciones sociales que los definen. Posteriormente, se aborda el concepto de territorio, entendido como construcción social y referente simbólico, más que como espacio físico, para comprender las dinámicas de los pobladores frente a los diferentes lugares del sector, así como los significados que se le atribuye a los mismos. 
Con estas bases, se defiende la tesis de que en la actualidad no es posible encontrar comunidades tal como se definen en su concepción tradicional, más bien, es frecuente encontrar que la solidez de los lazos sociales y comunitarios, fluctúa en razón de hechos concretos o emergentes. Estos lazos, sin embargo, y los acontecimientos que los permiten, los fortalecen o los debilitan, están determinados en ocasiones por el territorio, en este caso, el sector El Codito, con sus 17 barrios.

Metodológicamente se realizó una revisión de literatura, que diera cuenta de la evolución del término 'comunidad', con el fin de contrastarla con las realidades observadas en El Codito. Posteriormente, se definió una población específica, que pudiera ofrecernos respuestas sobre los procesos que nos interesaba indagar, una población que tuviera conocimiento del territorio, de sus dinámicas de poblamiento, de los hitos, ritos y personajes determinantes del sector, de la llegada y conformación de los actores y de los cambios y transformaciones en las relaciones sociales y en el territorio.

En últimas, pretendimos remitirnos a los primeros pobladores del sector que aún permanecen allí y que son tanto testigos, como constructores y participantes activos de todos estos procesos. Estos pobladores están representados por la población de adultos mayores, con quienes además el Instituto Rosarista de Acción Social Rafael Arenas Ángel — Seres- viene realizando desde el año 2007 un proyecto concreto denominado Sabiduría de los años, que se concentra en el fortalecimiento comunitario y el desarrollo de habilidades, a través de dos acciones concretas: la alfabetización y un taller productivo. Este proyecto ha generado por un lado, fuertes lazos de confianza con la población de adultos mayores y, por otro, la consolidación de un grupo con sentido de pertenencia e identidad.

En consecuencia, la información contenida en el presente texto, se limita a las percepciones y experiencias de la población de adultos mayores del sector, sin que esto indique que no se presenten otras dinámicas y experiencias valiosas, en otros grupos etáreos u organizaciones.

Considerando que la mayoría de los participantes en el proyecto Sabiduría de los años son pobladores iniciales del sector, nos concentramos en este grupo, para construir de su mano, la relación comunidad-territorio, a través de entrevistas no dirigidas, grupos focales y talleres. La información 
allí obtenida, nos permitió dilucidar algunas formas de asociación y prácticas comunitarias que se implementaron inicialmente, que bien se mantienen o que han desaparecido, y otras que se han generado con los años, no necesariamente como iniciativa comunitaria, sino como resultado de la oferta institucional con que cuenta el sector, y que son igualmente valoradas como positivas por la población de adultos mayores.

Las actividades realizadas, también arrojaron información importante sobre la percepción que tienen los adultos mayores de otros grupos poblacionales, como los jóvenes, y sobre la importancia de ciertos lugares específicos. El presente texto pretende dar cuenta de estos resultados encontrados, procurando siempre reflejar la voz de la comunidad.

\section{¿Es posible el sueño comunitario?}

El concepto de comunidad ha sido básico para el desarrollo de la teoría sociológica a través de los tiempos. Es así, como inicialmente se le otorga un carácter tradicional, auténtico e incuestionable, otorgable sólo a los grupos sociales primarios y precapitalistas, que se recuerdan con cierta melancolía y añoranza, para posteriormente adquirir una connotación esquiva, en la cual "Es difícil precisar si se trata de un concepto, de un tipo ideal, de una descripción socio-histórica, de un ideal regulativo, de un proyecto político, del fundamento último de todo análisis sociológico" (Bialakowsky, 2010, p. 4).

Partiendo de esta evolución del término y de la diversidad de significantes que se le pueden llegar a otorgar, nos propusimos identificar formas de construcción de comunidad, o de comunidades, en el territorio específico denominado sector El Codito, en caso de que estas efectivamente se presenten.

De acuerdo a la teoría sociológica clásica, la comunidad sólo se puede definir en contraposición a su sucesora natural la sociedad, que aparece como fin inevitable de cualquier proceso de desarrollo. Dentro de esta lógica, se suele ligar el surgimiento de la sociedad, con la formación de las ciudades, la definición del Estado y las formas de producción capitalista. Actualmente, ambos términos, tanto comunidad como sociedad, son sus- 
ceptibles de revisión y se cuestiona incluso la posibilidad de su existencia en un mundo globalizado y cambiante como en el que vivimos, en donde incluso los límites y potestades del Estado son difusos. Pese a esto, nos acogemos a la premisa de que en la actualidad "La indagación por la comunidad es, al menos inicialmente, una pregunta por el lazo social, es decir, por las formas de relación social —existentes, pasadas, imaginadas, ponderadas, supuestas-y sus maneras de integración” (Bialakowsky, 2010, p. 11).

Concebir una comunidad como la descrita por los clásicos es, si no un imposible, sí una condición en extremo improbable, que retaría todos los determinantes del mundo actual, caracterizado por el individualismo, el fácil acceso a la información y la desterritorialización, entre otros factores. No quiere decir, sin embargo, que no haya iniciativas legítimas y dignas de analizar; por ejemplo, las comunidades que se consolidan en torno a un hecho histórico muy fuerte y determinante; las comunidades de paz; las comunidades que se consolidan por iniciativa y convicción de sus miembros; las ecoaldeas; las comunidades que giran en torno a la figura de un líder; o las tradicionales que perviven, pese a todos los impases de la modernidad y la posmodernidad. Estos y otros casos, representan en justa medida lo que actualmente se podría considerar "comunidad", no obstante, el término se emplea sin discriminación para denotar cientos de fenómenos y sucesos sociales.

En su concepción clásica, la comunidad fue definida en términos de tradición, cohesión social, solidaridad, territorio y naturalidad, es así, como bajo diversas etiquetas los autores clásicos otorgan características particulares a la comunidad, que se oponen radicalmente a las características otorgadas a la sociedad. A grosso modo dichos planteamientos se pueden esquematizar como se muestra en la tabla 1:

Tal vez fue Tonnies el primero en establecer esta dicotomía entre comunidad y sociedad, que se mantendría latente en el desarrollo de teorías subsiguientes, "La comunidad no solamente aparece primero que la sociedad, sino que ella es primera, no sólo más antigua que la sociedad, sino anterior a toda distinción entre formas de vida en común" (Álvaro, 2010, p. 12). 
Tabla 1. Planteamientos clásicos de comunidad

\begin{tabular}{|c|c|c|}
\hline Autor & Comunidad & Sociedad \\
\hline $\begin{array}{l}\text { Ferdinand } \\
\text { Tonnies }\end{array}$ & $\begin{array}{l}\text { - Vida en común duradera y au- } \\
\text { téntica } \\
\text { - Organismo vivo } \\
\text { - Lo antiguo } \\
\text { - Voluntad esencial y natural }\end{array}$ & $\begin{array}{l}\text { - Artefacto mecánico, pasajero y } \\
\text { aparente } \\
\text { - Lo nuevo } \\
\text { - Voluntad racional o reflexiva }\end{array}$ \\
\hline $\begin{array}{l}\text { Max } \\
\text { Weber }\end{array}$ & $\begin{array}{l}\text { - Acción tradicional } \\
\text { - Sentimiento subjetivo de perte- } \\
\text { nencia común } \\
\text { - Natural y auténtica }\end{array}$ & $\begin{array}{l}\text { - Acción racional con arreglo a fines } \\
\text { - Acción racional con arreglo a va- } \\
\text { lores } \\
\text { - Burocracia } \\
\text { - Construida y manipulada }\end{array}$ \\
\hline $\begin{array}{l}\text { Emile } \\
\text { Durkheim }\end{array}$ & $\begin{array}{l}\text { - Solidaridad mecánica por simi- } \\
\text { litud } \\
\text { - Lazos profundos y continuos }\end{array}$ & $\begin{array}{l}\text { - Solidaridad orgánica por diferencias } \\
\text { - Basada en la división social del tra- } \\
\text { bajo especializada }\end{array}$ \\
\hline $\begin{array}{l}\text { Georg } \\
\text { Simmel }\end{array}$ & $\begin{array}{l}\text { - Vínculos naturales de adscripción } \\
\text { - Lo antiguo }\end{array}$ & $\begin{array}{l}\text { - Aislamiento de la personalidad } \\
\text { - Libertad individual }\end{array}$ \\
\hline
\end{tabular}

Fuente: elaboración propia

Desde este punto de vista, cualquier manifestación actual de grupos sociales específicos, que se unan en torno a situaciones o características particulares, no será más, que una mutación o un "mal sustituto" de las comunidades naturales primarias o de origen.

De acuerdo a la concepción de Tonnies, la comunidad implica un entendimiento tácito entre sus integrantes, por lo tanto, no es necesario consensuar o negociar y no hay lugar a desacuerdos o a críticas. Esta condición inicial genera muchos cuestionamientos, pues va en contravía a la concepción moderna de hacer política, que implica la discusión, el consenso, el escuchar la diferencia y el debate. Igualmente, choca con la concepción de sujeto social, aquel que debe ser contestatario frente a los modelos que se le imponen y cuyo deber es reivindicar diferentes formas de ver y hacer el mundo, en el marco de la diversidad. Como resultado, esta característica original otorgada a la comunidad, no encuentra actualmente ni vigencia, ni legitimidad.

Por otro lado, el hecho de que todos los individuos estén de acuerdo con una verdad que se les impone, como un todo incuestionable, se ve cla- 
ramente amenazado, si no imposibilitado, por las diferentes formas de interacción social que ofrece la vida moderna; prácticamente, en la actualidad no hay un grupo social totalmente aislado e incomunicado con el exterior. Así pues, la posibilidad de conocer diversos escenarios y formas de concepción del mundo, obliga a que la homogeneidad inicial que caracterizaba a los miembros de una comunidad, desparezca y dé origen a la diversidad de pensamientos, valores, convicciones y creencias. El aislamiento y la sostenibilidad de una comunidad dependerán entonces de un elevado grado de coerción, vigilancia y control.

Así, dentro de la concepción clásica, encontramos que el individuo desaparece para fundirse en un ente único y soberano: la com-unidad. No hay diferenciación, ni especialización entre sus miembros, todos hacen parte de un mismo cuerpo y se acogen a sus designios y normas preestablecidas. Así, la comunidad construye y determina su identidad, pero la construcción de identidad personal, es algo que solo será viable habiéndola superado.

Por su parte, Weber realiza su análisis partiendo de la definición de acción social, aquella que tiene un sentido y se orienta por las acciones de los otros. Toda acción social se define en términos de la propia cultura y se determina por sus preceptos; así, en la comunidad, las acciones estarán orientadas por la tradición, es decir, por las creencias cotidianas que se han legitimado y reproducido a través de los tiempos, mientras que en la sociedad, se añade a la acción social un componente de racionalidad, que puede estar sujeto a fines o a valores. Cuando la racionalidad está sujeta a fines, los sujetos actuarán en pro de los objetivos que pretenden alcanzar, y cuando está sujeta a valores, actuarán de acuerdo a sus convicciones consideradas verdaderas (Weber, 1994, pp. 6-7).

Tanto en el caso de la comunidad como en el de la sociedad, Weber reconoce la consolidación de distintos tipos de dominación y define a esta última, como la probabilidad de encontrar obediencia dentro de un grupo determinado, para mandatos específicos (Weber, 1994, p. 43). Los tipos de dominación legítima son: tradicional, basada en la creencia de la santidad de las tradiciones y en la legitimidad de las autoridades instauradas por ella; racional, basada en la creencia en la legalidad de las ordenaciones estatuidas; y carismática, basada en la creencia en una persona en particular, que 
ha demostrado heroísmo, ejemplaridad o santidad, en palabras de Weber, en un líder carismático. De acuerdo al análisis realizado, se defiende la idea de que en el caso específico de El Codito, la dominación legítima puede ser de tipo racional o en algunos casos, de tipo carismático. Esto se infiere por la adherencia a los mecanismos políticos instaurados en Colombia ${ }^{1}$ y por la importancia que se otorga a algunos personajes en particular, por lo general, ligados al ámbito político, como veremos posteriormente.

La diferenciación entre comunidad y sociedad, está representada en Durkheim por la división social del trabajo; afirmando, que es precisamente el trabajo el que determina las formas de interacción social. Este análisis se elabora en torno al concepto de solidaridad social, entendida como un fenómeno completamente moral, que se puede presentar de diferentes formas y que determina los niveles de cohesión social (Durkheim, 1995, p. 53).

En efecto, allí donde la solidaridad social existe, a pesar de su carácter inmaterial, no permanece en estado de pura potencia, sino que manifiesta su presencia mediante efectos sensibles. Allí donde es fuerte, inclina de manera firme a los hombres unos hacia otros, les pone frecuentemente en contacto, multiplica las ocasiones que tienen de encontrarse en relación (Durkheim, 1995, p. 53).

En este sentido, es precisamente la solidaridad la que potencia una comunidad y, en general, la que la posibilita. De acuerdo a lo observado en campo y a las percepciones de los pobladores de El Codito, nos atrevemos a afirmar que esta premisa sigue vigente y que se consolida como componente fundamental de cualquier comunidad. Respecto a la solidaridad también afirma Durkheim que “(...) Cuanto más solidarios son los miembros de una sociedad, más relaciones diversas sostienen, bien unos con otros, bien con el grupo colectivamente tomado, pues, si sus encuentros fueran esca-

1 Durante el año 2010, se realizó un diagnóstico poblacional en el sector, que arrojó los siguientes resultados en materia de participación electoral: el 94\% de la población votó para elegir presidente, el $62 \%$ para elegir alcalde, el 44\% para elegir concejales, el 43\% para elegir senadores, el $43 \%$ para elegir representantes, el 33\% para elegir ediles, el 30\% para elegir Junta de Acción Comunal y el 23\% para elegir Parlamento Andino (Equipo-Interdisciplinario-EstudiosDesarrollo-Local, 2010). Sin embargo, llama la atención, que la participación para elección de autoridades locales es mucho más baja que para autoridades distritales y nacionales. 
sos, no dependerían unos de otros más que de una manera intermitente y débil" (1995, p. 53)

Durkheim distingue dos tipos de solidaridad, la solidaridad mecánica o por semejanzas y la solidaridad debida a la división del trabajo u orgánica. El primero, corresponde al derecho represivo, es decir, aquel cuya ruptura constituye delito, reconociendo que todo crimen cumple con ciertas características habituales como: herir sentimientos comunes a todos los "individuos normales" de la sociedad y herir estados fuertes y definidos de la conciencia colectiva, por lo tanto, las reglas del derecho penal, expresan las semejanzas sociales más esenciales y corresponden a la solidaridad derivada de las semejanzas (ibídem, p. 65). También afirma que:

Existe una solidaridad social que procede de que un cierto número de estados de conciencia, son comunes a todos los miembros de la misma sociedad. Es la que, de una manera material, representa el derecho represivo, al menos en lo que tiene de esencial. La parte que ocupa en la integración general de la sociedad depende, evidentemente, de la extensión mayor o menor de la vida social que abarque y reglamente la conciencia común. Cuanto más relaciones diversas haya en las que esta última haga sentir su acción, más lazos crea también que unan el individuo al grupo; y más, por consiguiente, deriva la cohesión social de ésta causa, y lleva su marca (ibídem, 1995, p. 83).

El segundo tipo es el de la solidaridad orgánica, que aumenta con la actividad funcional de los organismos y que poco a poco le va restando terreno a la solidaridad mecánica. A ella corresponde el derecho cooperativo y pertenece más al ámbito individual, puesto que en ella, la conciencia colectiva se ha visto debilitada y deslegitimada. Así, afirma Durkheim, que los lazos sociales que se derivan de la división social del trabajo, son más numerosos y más fuertes que los que se derivan de las semejanzas sociales. Este tipo de solidaridad, será preponderante entonces en sociedades avanzadas.

Como común denominador en estas concepciones clásicas de comunidad, encontramos entonces la necesidad de algún tipo de dominación, para garantizar la cohesión y el funcionamiento como grupo social. 
Con la desaparición de las comunidades de origen, debida inicialmente a los procesos de industrialización y urbanización, la dicotomía entre comunidad y sociedad desaparece para dar paso a la nueva forma individuosociedad. Dentro de esta lógica, Simmel establece su planteamiento, enfatizando en el carácter individualista de la sociedad y en la tensión existente entre esta y el individuo como tal. Para Simmel,

Lo más antiguo es lo más simple menos especializado y menos articulado, resulta que no sólo en función de esto es accesible a una generalidad mayor, sino que ya lo es también puramente por ser el más antiguo, o sea que es el que con mayor seguridad se ha transmitido exterior e interiormente a cada individuo y por ello resulta más obviamente legítimo y depositario de valor (Simmel, 2002, p. 63).

La nueva sociedad se caracterizará entonces por su especialidad, su complejidad y su atemporalidad, de allí que la pérdida de la comunidad represente el logro de la libertad, toda vez que al desligarse de un grupo fuertemente cohesionado, mediado por la tradición, las creencias, la memoria colectiva y la aceptación sin cuestionamientos, el individuo adquiere la posibilidad de conocer otras realidades, de movilizarse a su antojo y sobre todo de diferenciarse de los demás. La diferenciación de un individuo de los demás, pasará a ser mucho más interesante que cualquier similitud con ellos, por ello, la diferenciación enarbola la bandera de la liberación. Para Simmel, sin embargo, esta pretendida liberación se puede entender también como algo problemático, al respecto afirma que "Los más profundos problemas de la vida moderna manan de la pretensión del individuo de conservar la autonomía y peculiaridad de su existencia frente a la prepotencia de la sociedad, de lo históricamente heredado, de la cultura externa y de la técnica de la vida" (ibídem, 2001, p. 107).

Así, la ruptura de la comunidad tradicional fue fundamental para el surgimiento del individuo, al permitir la capacidad de elegir, característica inseparable, no sólo del concepto de libertad sino también del de dignidad humana. 
Para los teóricos contemporáneos, la tensión entre comunidad y sociedad, deja de ser centro de atención, para en su lugar ahondar en las diferentes formas sociales propias de las sociedades modernas, o en las diferencias existentes entre estas últimas y las sociedades que las precedieron o que mantienen realidades consideradas premodernas.

Habermas, por ejemplo, ahonda en esta división entre las sociedades modernas y premodernas, para él "el mundo de la vida" representa el sentido compartido por un grupo determinado, que en sociedades premodernas estaba subordinado a lo sacro, por lo que no era cuestionable, y en las modernas se encuentra en constante revisión. Las "comunidades de comunicación" son propias de las sociedades modernas, que no son otra cosa que subculturas que desarrollan identidad personal y colectiva y que promueven estilos de vida alternativos y diversos (Bialakowsky, 2010, p. 14). Por su parte, Giddens habla de "comunidades reflexivas" caracterizadas por ser de fuerte intensidad, pero esporádicas y en permanente revisión, en las que no hay otro vehículo que permita entretejer las relaciones sociales, más allá de la reflexividad (ibídem, p. 23).

Bauman plantea que, en general, se tiene el sentimiento de que la comunidad es siempre algo bueno, que garantiza seguridad para sus miembros, pero que, sin embargo, representa la pérdida de libertad.

La seguridad y la libertad son dos valores igualmente preciosos y codiciados que podrían estar mejor o peor equilibrados, pero que difícilmente se reconciliarán nunca de manera plena y sin fricción (Bauman, 2003, p. 11).

En torno a esta dicotomía gira su planteamiento, en la búsqueda constante de comunidad, con posibilidades de vinculación a la misma, solo en la medida en que las libertades personales no se vean amenazadas o restringidas. De esta manera, los componentes de flexibilidad y temporalidad juegan un rol fundamental, ya que permiten, por un lado, la posibilidad de pertenecer a varias comunidades a la vez y, por otro, la posibilidad de renunciar a las mismas cuando así se desee. Se introduce entonces, el concepto de satisfacción que hace referencia a la pertenencia a una comunidad por elección y conveniencia, y en el cual, muy contrariamente a la idea original de comunidad, prima el interés particular sobre el general. Este fenómeno tiene múltiples respuestas y Bauman resalta el hecho de que las "obligacio- 
nes fraternales", tan características de la comunidad, son poco llamativas para los individuos que no solo se quieren diferenciar de "los otros", sino que además quieren ser reconocidos; el hecho de compartir beneficios y victorias, con quienes pueden no tener tantos méritos, no resulta apetecible.

Las nuevas dinámicas sociales han llevado a que en la actualidad se hable de "comunidades desechables", es decir, aquellas que se pueden consolidar en torno a un acontecimiento único, y que, por lo tanto, son de naturaleza superficial y episódica de los vínculos, aquellas en las que no hay compromisos a largo plazo, responsabilidades éticas, ni consecuencias. Muchas de estas características se han presentado en el sector El Codito, tal como lo expondremos más adelante.

La pérdida de la comunidad original, sin embargo, representó y tal vez siga representando, una necesidad de "recomunización" que ha adquirido diversas formas, desde los barrios obreros resultantes de la Revolución Industrial, hasta las nuevas comunidades basadas en afinidades, convicciones o intereses, que la mayoría de las veces tienen un carácter transitorio y flexible, es decir, que permiten el ingreso o salida de sus miembros al antojo de cada cual. Si los miembros dejan de encontrar en su grupo la satisfacción de sus necesidades particulares, fácilmente pueden abandonarlo y buscar otro nuevo que cumpla con sus expectativas.

Este planteamiento, que incluye aspectos de suma importancia como la temporalidad y la simultaneidad, y que se adapta más a las condiciones y modos de vida actuales, no obstante, no es del todo nuevo, ya Durkheim hacía referencia a la posibilidad de pertenecer a una comunidad en relación con un solo aspecto de la vida social, cuando hablaba de los "grupos profesionales", que tenían un carácter parcial, reconociendo que no necesariamente la comunidad se consolida como un "todo", sino que puede permear solo algunos aspectos de la vida de los individuos.

En estos términos, tal vez sea posible referirse a la población de El Codito como comunidad, o como comunidades parciales que se consolidan en torno a diversos factores, como edad, gustos, identidad barrial, intereses, grado de participación, apropiación de espacios y actividades conjuntas, entre otros, más no como comunidad totalizada. Esto se demuestra desde el punto de vista de las prácticas, de la relación de este territorio específico 
con el resto de la ciudad y más aún de la percepción de sus propios habitantes. De cualquier forma, coincidimos con Bauman cuando afirma que "El de comunidad es hoy otro nombre para referirse al paraíso perdido al que deseamos con todas nuestras fuerzas volver, por lo que buscamos febrilmente los caminos que puedan llevarnos allî” (Bauman, 2003, p. 9).

Así, el término "comunidad" tendrá una valoración positiva, que evoca fraternidad, unión y cohesión, y, de este modo, será motivo de evocación y deseo. En este sentido y para concluir con las concepciones de comunidad, podemos afirmar con Touraine que "A finales del siglo pasado, en plena industrialización del mundo occidental, los sociólogos nos enseñaron que pasábamos de la comunidad, encerrada en su identidad global, a la sociedad cuyas funciones se diferenciaban y racionalizaban. La evolución que hoy vivimos es casi la inversa" (Touraine, 1997, p. 12 ).

De esta manera, observamos nuevas necesidades de asociación, de identidad y de homogenización, que se hacen presentes en todos los ámbitos de la vida actual y que, por supuesto, no escapan a las lógicas particulares, de los habitantes de El Codito.

\section{Indicios y sentires de comunidad en El Codito}

El análisis de las particularidades de El Codito, consolidado como un espacio determinado y definido como "localidad" dentro de la lógica de división administrativa de Bogotá, se realizó con base a tres características propias de las comunidades de origen, como son: la homogeneidad de sus miembros, la diferenciación respecto de otros grupos sociales y la autosuficiencia.

Respecto a la homogeneidad, en este espacio confluyen diversidad de actores que distan mucho de ser similares entre sí, y que más bien se insertan en determinados subgrupos, definidos bien sea por afinidad, identidad, necesidad o por roles adjudicados o adquiridos. Dichos actores pueden hacer presencia permanente o no en el territorio, pero lo cierto es que lo afectan de manera directa o indirecta.

A partir del trabajo realizado en campo y de la presencia por más de tres años en el sector, hemos identificado algunos actores, que pueden ser 
endógenos o exógenos y que se clasifican según temática, grupo poblacional o carácter político. Dichos actores, que influyen de diversas maneras en los demás actores y que establecen variadas relaciones con el entorno y los otros se presentan en la tabla 2.

Tabla 2. Actores del sector El Codito

\begin{tabular}{|c|c|}
\hline Tipo de organización & Actores \\
\hline Centros educativos & $\begin{array}{l}\text { Colegio Don Bosco III, colegio Nuevo Horizonte, colegio Frie- } \\
\text { drich Naumann, colegio privado Los cerros y jardín infantil } \\
\text { Obra Suiza }\end{array}$ \\
\hline $\begin{array}{l}\text { Grupos de adulto } \\
\text { mayor }\end{array}$ & $\begin{array}{l}\text { Crear, Recordar es vivir, Sabiduría de los años, hogar San Ga- } \\
\text { briel, agricultura urbana Horizontes, Buenavista }\end{array}$ \\
\hline Asociaciones & $\begin{array}{l}\text { El Codito, Buenavista, Estrellita, Chaparral-Estrellita Horizon- } \\
\text { te, Brisas de Buenavista, Chaparral-Llanurita, Nuevo Progreso, } \\
\text { Asocerros }\end{array}$ \\
\hline $\begin{array}{l}\text { Medios de comunica- } \\
\text { ción }\end{array}$ & TV Unidos, Medios en común, Omega 7 \\
\hline $\begin{array}{l}\text { Juntas de Acción } \\
\text { Comunal }\end{array}$ & $\begin{array}{l}\text { Llanurita, Buenavista sectores I y II, La Franja, Las Mercedes } \\
\text { Norte, El Codito, Serrezuela, Mirador Norte parte alta, Balco- } \\
\text { nes de Vista Hermosa, Nuevo Horizontes, Chaparral, Mirador } \\
\text { Norte, Lomitas, Estrellita Norte, Horizontes }\end{array}$ \\
\hline Comités & Comité de vecinos Capilla \\
\hline Grupos de jóvenes & $\begin{array}{l}\text { Beat Down Entertaiment-Plasma, Gheto Estilo, Huellas, } \\
\text { Conjurarte, Puertas del Arte, Kalisaya, Agroecología, Mundo } \\
\text { Joven, Vínculos, Voces sin Atajos }\end{array}$ \\
\hline Instituciones distritales & UPA Codito, UBA Buenavista, Hospital de Usaquén \\
\hline Ediles & $\begin{array}{l}\text { Patricia Jerez, Liliana de Diago (ex edil), Luis Villamil, Ómar } \\
\text { Cárdenas (ex edil) }\end{array}$ \\
\hline Grupos de mujeres & Madres FAMI, Red de Mujeres \\
\hline Otras organizaciones & $\begin{array}{l}\text { Provivienda, Copevisa, Boys Scouts (dos grupos), Danza folcló- } \\
\text { rica Usaca, Universidad del Rosario }\end{array}$ \\
\hline
\end{tabular}

Fuente: Elaboración propia, basada en información construida por el equipo interdisciplinario de Estudios en Desarrollo Local.

Así, se podría afirmar que la necesidad de homogenización, se materializa básicamente en términos de edad — grupos de adultos mayores y 
grupos de jóvenes—, intereses políticos — juntas comunales, asociaciones, comités y personajes políticos—, grupos poblacionales específicos — mujeres-y sectores particulares —educación, cultura, vivienda y comunicación-. Los actores externos, habitualmente, están representados por las instituciones distritales o estatales, que, por su naturaleza, deben propender por la oferta de servicios y la garantía de derechos, y por organizaciones no gubernamentales o privadas, que igualmente brindan servicios.

En materia de diferenciación, las condiciones de la población de El Codito, así como las dinámicas de poblamiento del territorio, no son únicas o propias, sino que se asimilan en varios aspectos, a las condiciones de otros barrios ubicados en diferentes sectores de la ciudad. Al respecto, nos acogemos al planteamiento de Bourdieu, quien realiza un análisis social desde una nueva perspectiva, afirmando que las dicotomías de individuo-sociedad, individuo-colectivo u objetivo-subjetivo, planteadas anteriormente como verdad irrefutable, carecen de sentido aunque se hayan impuesto de manera tan contundente en el ámbito de las ciencias sociales (Bourdieu, 1997, p. 8 ). Él en cambio, propone una filosofía de la acción o relacional (basada en las relaciones) y disposicional, enmarcada en los conceptos de habitus, campo y capital.

Así, trasciende el concepto de sociedad, lo que da lugar al concepto de "espacio social", que se consolida como estructura de diferencia y se determina por la distribución de las formas de poder; estas últimas varían según los lugares y los momentos, es decir superan los límites del territorio y el tiempo. Esta teoría resulta muy interesante para el caso que nos ocupa, pues nos permite replantear los conceptos de comunidad y territorio, en donde el primero desparece para dar lugar a las asociaciones por afinidad y cercanía en el espacio social; y el segundo pierde el interés desde el punto de vista físico, dado que el espacio social es algo intangible e invisible.

Analizar las condiciones de El Codito a la luz de este planteamiento, resulta, a nuestro modo de ver, muy apropiado, pues consideramos que las prácticas y representaciones de los agentes, están más determinadas por aficiones y afinidades, que por factores relativos al territorio, al pasado común o al grado de cohesión social. Un ejemplo claro, es el de los jóvenes quienes se agrupan en torno al hip-hop, tanto en El Codito como en otros sectores 
de la ciudad, con los que se comparten características socio-económicas similares, en este caso, el hip-hop expresa una manera particular de pensar, de sentir y de ubicarse en el campo social, que se consolida como principio de diferenciación respecto a otras posiciones.

En cuanto a la autosuficiencia, no se puede afirmar que la población de El Codito tenga esta cualidad, muy por el contrario, sus pobladores deben buscar ofertas laborales, educativas, alimenticias y de salud por fuera del sector, vinculándose a los sistemas de seguridad social y educativo del Distrito, así como a los programas oficiales y extra oficiales que ofrecen las distintas entidades. Sin embargo, es importante mencionar experiencias como las huertas comunitarias, que permiten el autoconsumo de los productos cultivados y en ocasiones su comercialización, o las iniciativas productivas, como el taller de papelería y tarjetería de los adultos mayores, que genera beneficios a sus participantes.

Entonces, se puede concluir que como grupo social, la población de El Codito no se puede catalogar como comunidad en el sentido tradicional del término, dado que no cumple con sus principales virtudes. Se hace necesaria entonces, la identificación de otros factores que pueden facilitar o dificultar las prácticas comunitarias, y que dan indicios de la consolidación y fortalecimiento de los lazos sociales presentes en la población. Para tal fin, en esta primera parte del texto, nos centramos en el grupo poblacional de adultos mayores, considerando que desde su condición de fundadores de los barrios, pueden ofrecer una visión amplia del territorio y de la evolución de los procesos comunitarios.

En procura de esta identificación, y gracias a la participación libre, consciente e informada de los adultos mayores, en las diferentes acciones propuestas en la investigación, encontramos que esta población siente que vive en una comunidad, aunque no se logra poner de acuerdo para definir si había una mayor cohesión social al momento de la fundación de los barrios o en la actualidad. De esta manera, encontramos que el término comunidad se entiende como:

- Ser unido y asistir a reuniones

- Vivir acompañado 
- Estar juntos frente a determinadas coyunturas

- Acompañar y apoyar a los vecinos

- Identificar y elegir a las personas que están pendientes del barrio

- Participar de las reuniones de la Junta de Acción Comunal

- Difundir información importante a los vecinos

- Participar de las actividades que ofertan las instituciones

- Tener cariño hacia las personas

- Cuidarse unos a otros

- Mandar

- Estar pendientes de las cosas y vigilar

- Realizar actividades conjuntas como brigadas de aseo

- Comprenderse

- Consolidar una asociación de personas que se ayudan libremente

- El número de personas que habita el territorio ${ }^{2}$

De este modo, se le atribuyen al término valoraciones eminentemente positivas, aunque llama la atención, que pocos de los participantes reconocen la importancia de la organización y la estructuración de agendas, encaminadas al logro de objetivos o metas concretas. Se reconoce en cambio, la necesidad de buscar líderes, de establecer normas y de acogerse a ellas, en términos weberianos, podríamos afirmar entonces, que se otorga legitimidad a ciertas formas de dominación.

Al hablar de comunidad, en el caso particular de El Codito, los entrevistados hacen una diferenciación clara entre propietarios y arrendatarios, señalando a estos últimos de protagonizar escenas que perturban la tranquilidad del sector, a este respecto, también se afirma que es difícil consolidar comunidad, cuando la población es tan flotante. Otro reconocimiento importante es que la "comunidad" toma forma en situaciones coyunturales, es decir, tiene un carácter transitorio, en el cual, el ámbito de lo público se

2 Varios adultos mayores concuerdan en que antes en el sector no había comunidad, porque no había casi gente, pero afirman que actualmente sí la hay, porque es muy poblado. Esto indica que la noción de comunidad que predomina, no trasciende del número de personas que comparten un mismo territorio, sin ahondar en aspectos culturales o tradicionales, de convicción, de preferencia o de pasado común. 
fortalece con situaciones específicas, que al terminar, generan un retorno a la prevalencia del ámbito familiar, privado.

Al agrupar las opiniones de las participantes, se identificaron las siguientes categorías como fundamentales para la construcción y sostenibilidad de una comunidad: unión, organización, participación, cuidado y pertenencia. Sumado a estos factores, la población de adultos mayores otorga un reconocimiento a las JAC por su labor, por facilitar los trabajos comunitarios y por convocar, por diversos medios, a los habitantes del barrio, para la realización de jornadas comunitarias. Igualmente, se reconoce la importancia de la oferta institucional, en lo que se refiere a actividades, talleres y jornadas, para la integración y participación de la población de adultos mayores.

En las entrevistas se reseñan algunas prácticas comunitarias, que se realizaban inicialmente en el sector, pero que se fueron perdiendo con el paso del tiempo, entre ellas se encuentran:

- El cuidado de los hijos por parte de los vecinos, cuando los padres tenían que trabajar.

- El establecimiento de turnos entre las madres de familia, para el cuidado y alimentación de los niños en los jardines infantiles.

- La construcción en conjunto de vías, salones comunales o escaleras.

- La realización de actividades lúdicas (rifas, bazares, etcétera) para la recolección de fondos de uso común.

- El establecimiento de turnos de vigilancia en las noches.

- La carga de material para proyectos comunes.

La construcción de las casas, sin embargo, nunca se constituyó como trabajo comunitario, por el contrario, cada familia se debía hacer cargo de su vivienda, a excepción de los barrios Chaparral y Buenavista, cuya creación estuvo enmarcada en los procesos de Provivienda, que implicaban la construcción comunitaria de cada una de las viviendas familiares.

Con la información obtenida en las entrevistas efectuadas a los adultos mayores, se vislumbraron imaginarios propios de este grupo etáreo. Así, 
por ejemplo, con contadas excepciones, se asocia a los jóvenes con la rumba, el trago, la marihuana, las drogas, la calle, la inseguridad y los hurtos; igualmente, se atribuyen características a las mujeres y a los hombres, para explicar la baja participación de estos últimos en los talleres y actividades que ofrecen las distintas instituciones en el sector para ellos. Así, la mujer se reconoce como más comunicativa, comunitaria, servicial, trabajadora y responsable y el hombre como "mandón", orgulloso y desinteresado. Según las respuestas, las mujeres se apropian de los espacios comunitarios y se ocupan de las labores de la casa, mientras que los hombres ocupan su tiempo libre jugando naipe o tejo e ingiriendo bebidas alcohólicas en cantinas o tiendas. Si bien, los adultos mayores hombres tienen una muy baja participación en dichas actividades, tienen una participación más representativa en otros espacios más tradicionales y políticos, como las Juntas de Acción Comunal, las reuniones para temas electorales o para la toma de decisiones. Esto se puede deber a que posiblemente las mujeres encuentren en los espacios de los talleres, escenarios de participación que le fueron negados anteriormente, por esto, en ocasiones afirman que comenzaron a vivir ya de viejas y que agradecen enormemente las actividades y los momentos de encuentro con sus compañeras.

\section{Algunos momentos y personajes en la memoria de El Codito}

Respecto a los grandes hitos del sector, con los que se identifica la comunidad, se mencionan los siguientes:

- Instalación de la tubería

- Construcción del primer supermercado de frutas y verduras

- Pavimentación de las calles

- Recolección de agua en galones en la quebrada Zarauz

- Creación de las JAC

- Instalación de servicios públicos domiciliarios 
- Llegada del Plan Pisingo ${ }^{3}$

- Construcción de las vías

- Lavado de ropa en la quebrada

- Ayudas del Club Rotario

- Construcción del jardín infantil ${ }^{4}$

- Instalación de alumbrado informal

- Llegada de las rutas de transporte público

- Oferta de programas por parte de la Universidad del Rosario y de la Alcaldía

- Donación de una moto para vigilancia

- Otorgamiento del bono del Distrito

Estos momentos importantes se pueden ubicar entonces dentro de las siguientes categorías: servicios públicos, movilidad, abastecimiento de víveres, organización comunitaria e intervención de agentes externos. Respecto a las celebraciones, festividades o eventos, es importante mencionar que no se presentan de manera autóctona en El Codito, es decir, no hay festividades propias del sector. Sin embargo, se presentan algunas prácticas como la "Semana por la paz", que si bien no nace allí, sí se ha institucionalizado desde hace algunos años, contando con la participación de diferentes sectores de la población.

Como se mencionó anteriormente, Max Weber introduce la figura del líder carismático; aquel que posee la facultad de aglomerar, movilizar y cohesionar un grupo social, en pro de intereses comunes. La figura del líder ha sido clave para el entendimiento de los procesos comunitarios en el sector El Codito, ya que este grupo social se siente comunidad en escenarios y coyunturas específicas, y a la luz de personajes concretos y recordados. Estos líderes, sin embargo, no han representado en todos los casos los intereses de la mayoría, sino que son también, en ocasiones, quienes detentan el poder económico, político o de la fuerza. En este caso concreto, algunos se

\footnotetext{
3 Apadrinamiento de niños y préstamos a las familias.

4 Todos los padres de familia cargaron material desde abajo y agua en galones para los niños.
} 
consolidan como dueños iniciales de la tierra, administradores de la misma, presidentes de juntas comunales o prestadores de servicios.

Como resultado del ejercicio de recopilación de información realizado en el sector, se identificaron los siguientes personajes como los más recordados dentro de la población de adultos mayores.

Presidentes de Junta de Acción Comunal: la información obtenida en las entrevistas y en los talleres, permitió establecer la cronología de los presidentes de la JAC del barrio Horizontes, de esta manera:

- Eugenio Montenegro

- Peña

- Clodomiro Simijaca

- Rafael Vela

- Salomón Conde

- Jorge Guzmán

- Hernando Palomino

- María Jesús Viejo (Chus)

Del barrio El Codito, se recuerda a Miriam Puerto como una mujer muy activa y trabajadora, en la plenaria se le reconoció como: "Luchadora. Colaboraba con su pueblo. Fue presidenta de junta, como seis años. Ella hizo mucho, mucho por el barrio. Colaboró para las casitas que eran en tela, en paroid. Así empezamos todos (...)". ${ }^{5}$

No se posee información de los otros presidentes, ni tampoco de los presidentes de otros barrios.

José Domingo Cristancho: este personaje es recordado como el propietario inicial de los terrenos que actualmente conforman el barrio Horizontes. Fue él quien vendió los lotes a los pobladores iniciales del barrio y, en general,

5 Los testimonios registrados en adelante, son apartados de las entrevistas a profundidad realizadas a los adultos mayores del sector. 
42

es percibido como un obstáculo para la consecución de las escrituras de los mismos.

Al respecto se obtuvieron los siguientes testimonios:

Le pagaba cuotas pero él se perdió, no sabíamos para donde se fue ni donde ir a pagarle. Yo le debía $\$ 6700$ y un buen día alguien me dijo que él tenía una oficina en la Avenida Jiménez con décima. Me fui con otra persona y allí le encontré en el sexto piso. Le pregunté cuanto le debía. Él dijo que $\$ 180000$. El lote se lo había comprado en $\$ 33000$. Él dijo que yo me había perdido. Dijo que por los intereses, la mora. Yo estuve pensando y le dije "sí le voy a pagar pero estoy pensando cómo hacer. Ir y conseguir quien me compre el lote, venir y pagarle a usted y coger mis chinos y bajar por donde mismo subí porque no me queda otra alternativa. Yo no tengo esa plata. Vine acá, hablé con el Presidente de la Junta, no me acuerdo bien si era Peña...

Entonces yo vine, le conté y me dijo que no solo era yo la del problema. Nos reunimos en el salón comunal, que ya existía este, y éramos 60 que teníamos el mismo problema. ¿Qué hicimos? Nos reunimos como diez y nos fuimos otra vuelta a la oficina de Cristancho y le convencimos para que viniera aquí a una reunión con nosotros. Ese día esto se llenó y llegamos a un arreglo de que yo no le pagaba los $\$ 180000$ sino $\$ 40000$. Pero había otro problema, que mi esposo ya había muerto y él ya había vendido la mitad. iDe dónde saco yo los $\$ 40000$ ? Fui donde don Marcos que era al que le habíamos vendido y le conté el problema. Dijo, hágame un favor, como yo estoy recién entrado a mi trabajo no puedo sacar ese piso, pero hable allá como cosa suya y yo le colaboro, que ya es otra voz. Pida toda la rebaja que pueda y yo le colaboro. Así fue, quedaron $\$ 45000$. Él me dio $\$ 21000$ y ya fue cuando me hicieron escritura, que salimos 25. Nos cobraban $\$ 5000$. En ese tiempo era una plata. Después que $\$ 100000$, que $\$ 200000$ Una doctora sí vino. La doctora Gladys sí nos hizo las escrituras, los primeros somos 25 y de ahí el resto a bregar a que les hicieran sus escrituras.

Esto (el barrio Horizontes) era una finca, un terreno, y nosotros compramos estos pedazos acá, y como no había nada, ni luz ni nada, el baño 
lo hacíamos por ahí por este monte. El agua, de donde sube la quebrada de la séptima donde sube la avenida para acá, a la espalda, en burro, en volqueta, a construir, a lavar, nos tocaba ir a la una, dos de la mañana, porque eso era un hervidero. Era cantidad de gente que venía de todos los lados.

Se discutió entre todas las participantes que antes del señor Cristancho había otro dueño de los terrenos. Al respecto se afirmó:

Sí claro, pero no se sabe cómo se llamaría. Tenía otra finca debajo de la séptima. Se cogió una plata, y esa plata se la quitó el banco del Estado. Hasta ese momento era todo lo que se había sabido. Por eso le quitaron la finca de abajo. Por allí para el sur, por el Chaparral. Él estuvo preso, lo encarcelaron. A mí en ese tiempo me vendieron por $\$ 27000$ el lote. Yo le estaba pagando a él las cuotas como de $\$ 2000$ pesos. Eso era poquito. Después ya vino la abogada y me dijo que le debía $\$ 70000$. Entonces fui allá y dije que no debía nada. Y gracias al señor Simijaca, que eso sí se lo agradezco. Yo venía con los papeles y le conté lo que me pasaba. Me dijo que no le pagaría ni un peso al señor Cristancho, porque ya había pagado. Ya haga su escritura. Simijaca me sacó de ese pleito y listo. Contrató a la doctora Gladys, nos reunimos acá y él fue sacando escrituras. Nos cobró $\$ 45000$ por la escritura del doctor Cristancho.

Próspero: este personaje fue recordado en algunas de las entrevistas como uno de los representantes de Provivienda, sin embargo, no fue mencionado de manera importante en la plenaria general realizada con las participantes de las entrevistas.

Juan Albarracín: recordado como patrón de obras del barrio Horizontes.

Roberto: recordado como la persona que disponía sobre la propiedad de los lotes. Al respecto se obtuvo el siguiente testimonio: 
Él era de acá de este barrio de Horizontes. Él era el que mandaba todo esto de la finca, desde debajo de la séptima hasta acá el Mirador, él cuidaba una casa grande. Con la señora Isabel, la esposa. Y después de que el doctor Cristancho le compró al dueño, no sé quién sería, entonces ya a Roberto lo dejaron allá. Un pedazo. Como cinco o seis lotes le dejaron a él. Ellos eran los que cuidaban todo esto. Se hizo cargo allá donde lo dejó don Cristancho. Ya fue cuando él echó a urbanizar el primer sector de acá, después el segundo sector de aquí para allá... Yo no lo recuerdo a él, pero sí donde vivía, la casa. La Fronterita se llamaba eso. Sí. La hija Isabel, se perdió por aquí. Era una persona muy buena gente. Cuando yo lo traté a él y a la esposa, eran muy buenas personas.

Jairo Urrego: mencionado en alguna de las entrevistas como "supervisor del barrio", no fue tan recordado en la plenaria.

Rafael Vela: presidente de Junta de Acción Comunal. "Ese, que duró aquí cuatro años, que apoyaba y anduvo y recogió para comprar los utensilios para las escobas, para los traperos, para todo eso, que por ahí estaba trabajando, yo no sé cuanto porque no viene por acá.”

José: algunas personas son recordadas por la mayoría de las participantes con mucho cariño, tal es el caso de don José, un médico de profesión que brindó sus servicios de manera especial a la comunidad. De él se dice que fue secuestrado y asesinado. "Amaneció en el apartamento amarrado con los cordones de los zapatos. No sé sabe quién ni por qué pudo hacerlo. Era una gran persona."

Carlos Arango: este personaje es recordado por ser el propietario de una de las primeras tiendas en el barrio, también se asocia con la venta de licores.

Muñoz: fue un concejal muy recordado en la comunidad, por haber gestionado varios asuntos referentes a servicios públicos. 
Domingo Rivera y Carmelita: esta pareja de esposos es recordada por ser dueña del primer restaurante del sector, una pollería.

Otros actores del sector: Giddens, observa un aspecto muy interesante relacionado con la valoración de la comunidad, ya que si bien en general se otorga a la misma un significado positivo, se reconoce que no siempre las "comunidades" tienen un buen interés, ya que pueden incluso intensificar desigualdades o consolidar poderes.

A la luz de este postulado, se puede analizar el caso de las pandillas o grupos delincuenciales juveniles que generan una identidad y códigos propios, que los diferencian de los demás y que determinan patrones de comportamiento. En el caso de El Codito, algunos de estos grupos incluso se han consolidado inicialmente en torno a familias concretas y han impuesto sus normas y afianzado sus poderes con claras delimitaciones territoriales; son reconocidos por toda la comunidad y al ser protagonistas de diversos actos considerados violentos, muchos han sido asesinados.

Algunas familias reconocidas como problemáticas, pertenecen al sector, otras en cambio, surgieron en barrios aledaños. Respecto a las primeras, la comunidad menciona: "Son bien renombrados. iAy si! (...) Siempre han sido de allá de Mirador. Ellos son del Mirador pero bajan aquí (...) Es que ellos son hartos y viven en distintos predios. Es que les han dado duro. Por pícaros. Muy vengativos. Muy buscarruidos. Y es que ellos se forman como una pandilla. Sí, pandilleros”.

Respecto a las familias problemáticas del sector y las de barrios aledaños, se dice que:

(...) Pues son pandillas como enemigas. Ellos tienen que respetar sus espacios. Los últimos que dejaron los dejaron allá en el Castillo. Ahí en el piso. Mataron a gente. Existen hace como 25 años. Pero siguen. Eran poquitas casitas. Donde había una peñita, tomaban, comían y cuando les cobraban entonces agarraban la casa a piedra. También ellos tenían

6 Los extractos presentados a continuación, hacen parte de algunas de las entrevistas realizadas para la investigación. 
miedo. Ya veían que llegaban, e inmediatamente cerraban las puertas. La situación con ellos está mejor ahora que hace unos años. Han ido muriendo muchos. Los mataron. Ya no, ya los que quedan son muy poquitos.

(...) Yo tengo un hijo que uno de esos lo apuñaló (...) Yo recogí mi chino envuelto en una sábana y me lo llevé para el (Hospital) Simón Bolívar. Y era una pluma de sangre que salía de él. Pero nosotros no cobramos venganza con ellos. Eso quedó así.

(...) Y ya le digo, la mayoría de los mayores ya murieron y ya de pronto hay por ahí nietos o bisnietos, pobrecitos quién sabe qué será de ellos.

De otra familia denominada La Tribu, se menciona que: “(..) Ellos viven aquí en Chaparral (...) Como le digo, ellos se agarraban entre sí, no sabían ni quien era la mamá, ni la nuera ni nada. Pues ahí salía hasta la abuelita."

Así, los personajes y actores de mayor recordación en El Codito, dentro de la población de adultos mayores, están asociados al ámbito político, al monopolio de la propiedad, a la prestación de servicios comunitarios y a la generación de conflictos y violencia.

\section{La relevancia del territorio en la construcción de comunidad en El Codito}

La inestabilidad es un lugar del que puede disfrutarse. Zygmunt Bauman. Comunidad, en busca de seguridad en un mundo hostil

La idea original de comunidad está estrechamente ligada al concepto de territorio, por representar este último el arraigo y por determinar muchas tradiciones y dinámicas propias de los grupos sociales. De esta manera, las comunidades establecen diversas formas de relacionarse con el territorio y le atribuyen al mismo diferentes significados; se construyen así los lugares sagrados, los lugares de esparcimiento, los lugares políticos y en fin, los lugares que dan forma a todas las manifestaciones de la vida social. Cada 
lugar será entonces testigo y actor de la vida de sus habitantes, al consolidar tradiciones, narrar historias y construir memoria.

El desvanecimiento de las fronteras, la velocidad y la accesibilidad, sin embargo, obligan a una reconceptualización del territorio, o mejor del espacio, en la que no será tan importante la consideración del espacio físico, como sí, la construcción social de espacios virtuales o "no reales", que, además, están llenos de significado y determinan actitudes y prácticas. En cualquier caso, el territorio se debe entender siempre como una construcción social, en la que mediarán diferentes variables particulares para cada caso. En este sentido, afirmamos con Chávez que: "El territorio, por principio, no es un espacio virgen, indiferenciado y neutral que sólo sirve como mero contenedor de la vida social y cultural, sino que se trata siempre de un espacio que ha sido valorizado ya sea instrumentalmente (bajo el aspecto ecológico, económico o geopolítico), o valorado culturalmente (bajo el ángulo simbólico-expresivo) (Chávez, s. f., p. 27).

Todo territorio se definirá entonces, en términos de los significados que le han sido atribuidos, que se pueden transformar o revalorizar, dependiendo de los actores o de los tiempos. Estos significados llenan de contenido el simple espacio físico y le otorgan un estatus de reconocimiento y legitimidad, dentro de las comunidades que lo usan, lo habitan o lo apropian. También Foucault hace énfasis en las características particulares que generan identidad, ya no en términos de territorio, sino de espacio; al respecto afirma:

No vivimos en un espacio homogéneo y vacío, sino, antes bien, en un espacio poblado de calidades, un espacio tomado quizás por fantasmas: el espacio de nuestras percepciones primarias, el de nuestros sueños, el de nuestras pasiones que conservan en sí mismas calidades que se dirían intrínsecas; espacio leve, etéreo, transparente o, bien, oscuro, cavernario, atestado; es un espacio de alturas, de cumbres, o por el contrario, un espacio de simas, un espacio de fango, un espacio que puede fluir como una corriente de agua, un espacio que puede ser fijado, concretado como la piedra o el cristal. (Foucault, 1967, p. 2) 
Foucault sostiene que la obsesión del siglo XIX fue la historia y que nuestra época es la época del espacio, para él, vivimos en el tiempo de la simultaneidad, de la yuxtaposición, de la proximidad y la distancia (ibídem, p. 1). El espacio, sin embargo, es también para Foucault una experiencia occidental, que tiene una historia particular; así, el espacio en la edad media era un conjunto jerarquizado de lugares, en el que unos se superponían a otros, configurando un espacio de localización. En este momento se tenía un ideal finito del espacio, que queda rebatido con los planteamientos de Galileo, quien erige un espacio infinito, en el que se remplaza la localización por la extensión. En la actualidad, la extensión se ve sustituida por la ubicación, que se define en términos de vecindad y de las relaciones que esta genera ${ }^{7}$ (ibídem, p. 1). Así, los espacios están definidos siempre en términos de relaciones, que, por supuesto, se consolidan como relaciones de poder.

En este sentido, al igual que el concepto de comunidad, se puede afirmar que el concepto de territorio se define también en términos de poder, encontrando que algunos lugares no son de libre acceso y están reservados solo para algunos miembros de la comunidad, sustentándose bien sea en normas establecidas o implícitas. Tal es el caso de algunos lugares considerados sagrados o de espacios que son apropiados por pequeños grupos, al establecer delimitaciones territoriales y fortalecer identidades. Respecto a la definición de territorio en términos de poder, afirma Chávez que:

Podemos hablar de las relaciones entre un grupo social y su territorio en términos de las relaciones de poder que lo definen y delimitan, de las instituciones que lo articulan y moldean, de la forma como se refieren los individuos a él y lo integran a su cultura y a su visión del mundo, de la manera en que lo transforman y modifican, o de como los límites físicos limitan el juego del poder y las propias relaciones sociales (s.f., p. 26).

$7 \quad$ El término vecindad sin embargo, ya había sido acuñado por Tonnies para la definición de las comunidades primarias y hacía referencia a la confluencia del espacio de vivienda con el espacio de trabajo. 
Así, el territorio se debe entender también como el marco de distribución de instituciones, actores y prácticas culturales particulares, y como las relaciones que se posibilitan entre ellos, y que generan, en ocasiones, pertenencia e identidad. En este sentido, el territorio más que algo físico, es un referente simbólico.

A diferencia de otros barrios, los del sector El Codito no se constituyeron en torno a un espacio público importante (plaza, iglesia, etcétera), consideramos que por ello, para sus habitantes no hay lugares muy representativos o simbólicos, las opiniones se dividen en lugares de comercio (tiendas, supermercados), lugares de especial importancia para los adultos mayores, como los puestos de salud o las iglesias, lugares que fueron importantes en el momento de fundación de los barrios, como la plaza de mercado de San Cristóbal, el primer jardín infantil —onstruido y mantenido con el esfuerzo de toda la comunidad-, la tienda de licores de Carlos Arango y la quebrada Zarauz o la de Servitá, y lugares y referentes espaciales de importancia actual como El Castillo, el colegio Don Bosco, el colegio San Juan en Usaquén y la huerta comunitaria.

El lugar más reconocido y legitimado por los pobladores del sector es el salón comunal que se consolida como el espacio de encuentro por excelencia, donde se toman decisiones, se realiza actividades recreativas y se efectúan reuniones. También se tienen referenciados espacios considerados negativos para la comunidad, como los expendios de droga u "ollas", en especial se menciona uno que está muy cerca al CAI (Comando de Atención Inmediata). Llama la atención que los parques no son nombrados como espacios de importancia para la comunidad de adultos mayores, lo que puede responder a la escasez de los mismos, al mal estado en el que se encuentran, a que se asocian con la inseguridad y el consumo de drogas, o a que son apropiados por otros grupos poblacionales.

Cada barrio tiene su memoria, sus hitos, sus territorios y sus actores, aunque muchas características son compartidas por todos los barrios del sector, según lo evidenció un diagnóstico poblacional realizado por la Universidad del Rosario en el año 2010. Barrios como Serrezuela, por ejemplo, carecen de servicio de acueducto y se proveen de agua con el limitado abastecimiento que ofrecen los carrotanques de la Empresa de Acueducto 
de Bogotá, para sus habitantes, este es el único problema del que adolece su comunidad, conformada por aproximadamente 80 personas, no se mencionan aspectos de seguridad o violencia, que sí se consolidan como común denominador de los barrios aledaños.

$\mathrm{Al}$ indagar por la historia y prospectiva de los barrios, identificamos algunos adjetivos de connotación negativa, en general, que se adjudican a cada uno de ellos y que se pretendieron sintetizar en el gráfico 1.

Gráfico 1. Propiedades de los barrios según la percepción de los habitantes del sector

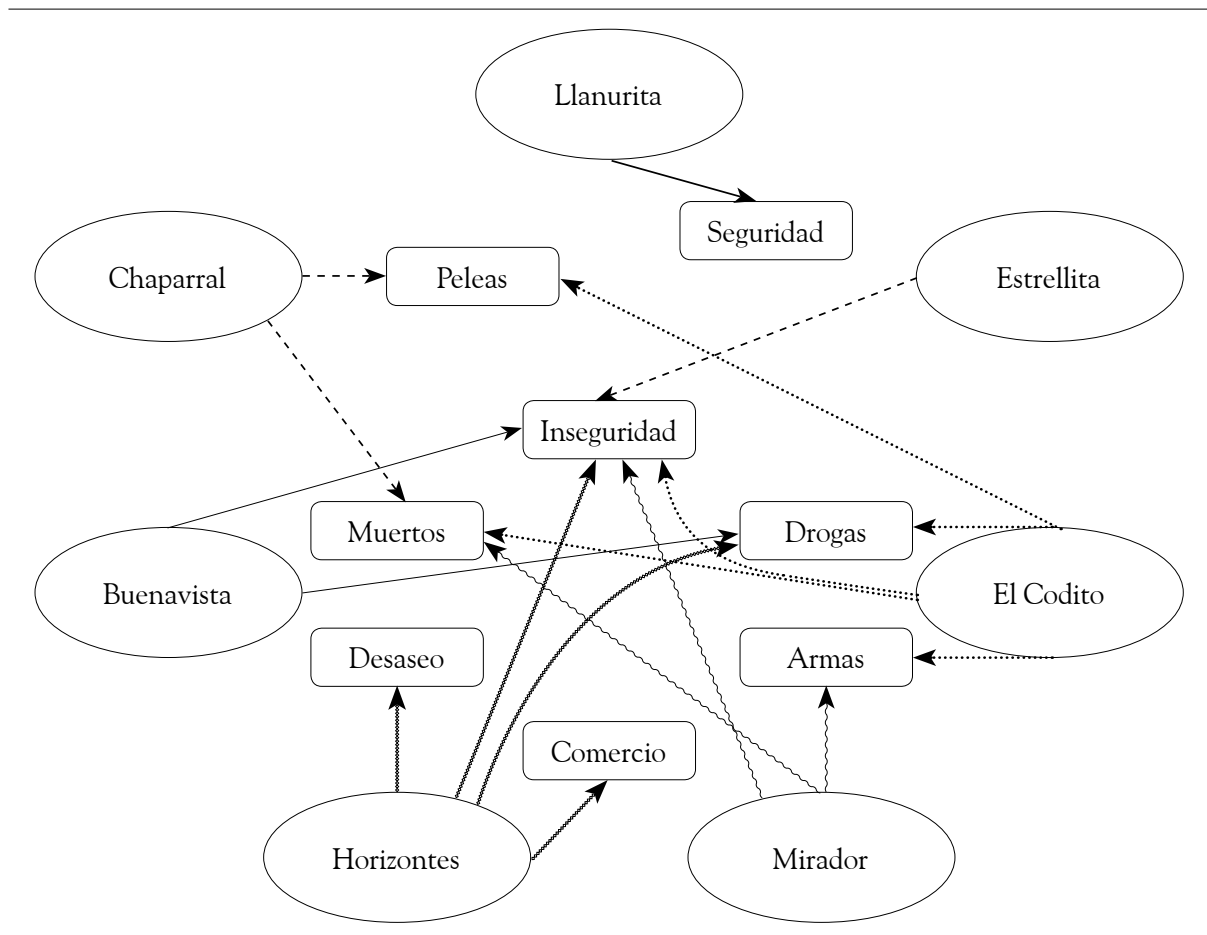

Fuente: elaboración propia

Como se puede observar, el único adjetivo positivo fue el de seguridad, adjudicado al barrio Llanurita, en donde se dice que gracias a su tamaño pequeño, no se han presentado atracos ni actos violentos, a diferencia de otros barrios en los que son común denominador. Así, la inseguridad se consolida como característica determinante de los barrios Mirador, Estrellita, El Codito, Horizontes y Buenavista, sin embargo, todos estos barrios 
no fueron inseguros siempre, de acuerdo a los testimonios de las personas entrevistadas, el sector era seguro hasta que se empezaron a construir los barrios Estrellita, Mirador y Buenavista, aún en la actualidad es común escuchar que la inseguridad viene de los barrios de arriba.

En general, todos los entrevistados concuerdan con que inicialmente el territorio era netamente rural y estaba constituido por potreros y matorrales, algunas familias se dedicaban a la cría de animales como marranos y ovejas, las viviendas eran precarias, construidas en tabla o en poli sombra y sin acceso a servicios públicos.

Como características particulares de cada barrio, se identificaron en las entrevistas las siguientes:

Tabla 3. Características de los barrios según los habitantes del sector

\begin{tabular}{|c|l|}
\hline Barrio & \multicolumn{1}{c|}{ Características } \\
\hline Llanurita & $\begin{array}{l}\text { Inicialmente, estaba compuesto por 35 familias. } \\
\text { Se utilizaba el "recibo de contribución", como una modalidad de pago de } \\
\text { impuestos. } \\
\text { Actualmente, no hay salón comunal, ni Junta de Acción Comunal. }\end{array}$ \\
\hline Chaparral & $\begin{array}{l}\text { Hizo parte del proceso Provivienda, de loteo y autoconstrucción. } \\
\text { Eran frecuentes las peleas y pedreas con la policía, en el marco de la apro- } \\
\text { piación de los lotes. }\end{array}$ \\
\hline Horizontes & $\begin{array}{l}\text { Pertenecía a José Domingo Cristancho. } \\
\text { Antes de la llegada de los servicios públicos, se construyó una letrina comu- } \\
\text { nitaria. }\end{array}$ \\
\hline Mirador & Se referencian permanentemente agentes de conflicto. \\
\hline
\end{tabular}

Fuente: elaboración propia

De esta manera, se presentan imaginarios y significantes de cada lugar y barrio, que parecen ser compartidos por la población de adultos mayores del sector, que, sin duda, variarán para los demás grupos etáreos y poblacionales.

Compuesto por 17 barrios y habitado por aproximadamente 32000 personas, el sector El Codito es absolutamente diverso y permite la formación de lazos sociales, en ocasiones muy fuertes, difusos y difíciles de percibir. 


\section{Conclusiones}

De acuerdo al análisis realizado, se puede afirmar que constantemente se construyen y reconstruyen comunidades, que guardan en ocasiones propiedades de las comunidades de antaño, pero que rara vez cumplen con todas sus características. No es posible entonces, hablar de "comunidad" en el sector El Codito, sino de comunidades y lazos sociales que se muestran más fuertes en ocasiones y más esquivos en otras. Es así, como la lucha por los servicios públicos es un gran hito dentro de la memoria colectiva de algunos de los barrios que componen el sector y tal vez sea la inspiración de nuevos barrios emergentes, que tienen un gran camino que recorrer en ese sentido. El territorio es otro componente que puede determinar a los habitantes del sector como "comunidad", sin embargo, el primer paso para que sea realidad es el auto reconocimiento como tal. El discurso de los líderes se enmarca en este sentido, aunque su poder de representación es cuestionado por situaciones como la baja participación de los habitantes en los espacios oficiales, o la solución de conflictos de orden social o comunitario.

Los actores identificados en el sector son de diversa índole y pueden ser internos o externos, de esta manera, se reconocen principalmente los grupos organizados en torno a: la edad de sus miembros, los intereses políticos, los intereses específicos y las instituciones prestadoras de servicios tanto del orden público, como del orden privado.

En general, para los participantes en este estudio, la comunidad tiene una connotación positiva, ligada a procesos solidarios, de trabajo en conjunto y de lucha por el logro de objetivos comunes. Se mantiene la idea de que la comunidad crece proporcionalmente al aumento de la población que habita un territorio, en este sentido, se confunde el término con la mera aglomeración de los habitantes de un lugar.

Hay una valoración positiva de las instituciones que hacen presencia en el sector, a través de programas y proyectos. Respecto de la atención que se le brinda al adulto mayor, también es importante mencionar los bonos que reciben de la Secretaría de Integración Social, a través del programa Subsidios económicos para personas mayores, pues son reseñados como una 
gran ayuda para el pago de servicios y alimentación, que, sin embargo, no dejan de generar conflicto al interior de las comunidades, pues no tienen una cobertura total y para poder acceder a ellos es necesario anotarse en una lista y esperar a que alguno de los beneficiarios fallezca, para otorgar el bono a un nuevo beneficiario. En ese sentido, la oferta institucional aunque percibida como positiva y en ocasiones como potenciadora de procesos comunitarios, se queda corta a la hora de brindar cobertura y calidad.

Los hitos del sector se relacionan principalmente con: la lucha por los servicios públicos y de movilidad, el abastecimiento de agua y víveres, la organización comunitaria y la intervención de agentes externos. En cuanto a ritos, se encontró que si bien no hay celebraciones autóctonas, se ha implementado el desarrollo de actividades y eventos, que cuentan con la participación y el reconocimiento de varios sectores poblacionales.

Cada uno de los 17 barrios de El Codito, tiene lugares y momentos específicos, que consolidan y fortalecen la memoria colectiva de sus habitantes y potencian o debilitan procesos comunitarios. También llama la atención, la dificultad para reconstruir la memoria colectiva de estos barrios, con excepción del barrio Horizontes, en el que se mantienen en el recuerdo de muchos de sus habitantes, sus procesos de poblamiento y de urbanización, así como los personajes que han hecho parte de los mismos.

En general, se han construido imaginarios negativos en torno a los diferentes barrios, así, se identifican características comunes a todos ellos, que tienen que ver con inseguridad, violencia y drogas. Por otro lado, por parte del grupo de adultos mayores, no hay apropiación de los espacios públicos, como parques o zonas abiertas para ellos, en cambio el salón comunal cobra vital importancia, al consolidarse como escenario de participación, recreación y encuentro.

\section{Bibliografía}

Álvaro, D. (marzo, 2010). Los conceptos de comunidad y sociedad de Ferdinand Tonnies. Papeles del CEIC, 2010/1 (52), pp. 1-24. 
Bauman, Z. (2003). Comunidad, en busca de la seguridad en un mundo hostil. Madrid: Siglo XXI de España Editores.

Bialakowsky, A. (2010). Comunidad y sentido en la teoría sociológica contemporánea: la propuesta de A. Giddens y J. Habermas. Papeles del CEIC, 2010/1(53), pp. 1-30.

Bourdieu, P. (1997). Razones prácticas sobre la teoría de la acción. Barcelona: Anagrama.

Chavez, T. (s.f.). Tiempo y espacio, territorio y memoria. Revista Universidad de Sonora, (21), pp. 25-28. Recuperado de http://www.revistauniversidad. uson.mx/revistas/21-Tiempo\%20y\%20espacio\%20territorio\%20y\%20 memoria.pdf

Durkheim, E. (1995). La división social del trabajo. Madrid: Akal.

Foucault, M. (14 de marzo de 1967). Los espacios otros. Conferencia dictada en el Cercle des études architecturals.

Guevara, J. \& Mendoza, M. (2011). Retos y avances del desarrollo local, caso El Codito. Bogotá: Universidad del Rosario.

Luna, E. (2010). Experiencia de apoyo al desarrollo local en el sector El Codito. En Universidad del Rosario. Universidad y sociedad, extensión universitaria, conocimiento y redes sociales (pp. 109-139), Bogotá D. C.: Autor. (Colección de Extensión).

Pérez, J. P. (enero de 2006). Globalización y comunidad de vecindad. Iconos Revista de Ciencias Sociales (24), pp. 27-42.

Simmel, G. (octubre, 2001). El individuo y la libertad. Ensayos de crítica de la cultura. Las grandes urbes y la vida del espíritu. Revista de Estudios Sociales, (10), pp. 107-109.

Simmel, G. (2002). Cuestiones fundamentales de sociología. Barcelona: Gedisa Editorial.

Touraine, A. (1997). ¿Podremos vivir juntos? Iguales y diferentes. Buenos Aires: Fondo de Cultura Económica de Argentina S. A.

Weber, M. (1994). Economía y sociedad. Bogotá: Fondo de Cultura Económica. 